\title{
Application of Float Glass for Car Windshield
}

\author{
Eko Julianto ${ }^{1}$, Marwan Effend $\mathbf{y}^{2 *}$, Gunarto ${ }^{3}$ \\ ${ }^{1,3}$ Department of Mechanical Engineering, Universitas Muhammadiyah Pontianak,78123, Indonesia. \\ ${ }^{2}$ Department of Mechanical Engineering,Universitas Muhammadiyah Surakarta,57102, Indonesia. \\ *Marwan.Effendy@ums.ac.id
}

\begin{abstract}
A front windshield forming process traditionally has to be performed on cars for broken glass accidents. The objective of study is to evaluate the characteristics of float type flat glass which is commonly used in forming process of the car front windshield. Specimen made of float glass with a thickness of $5 \mathrm{~mm}$, width $84 \mathrm{~cm}$ and length of 135 $\mathrm{cm}$ was tested in high temperature heating furnaces up to $1600^{\circ} \mathrm{C}$. Key important parameters such as deflection $(\Delta \mathrm{L})$ andsize area(A)were carefully observed during the experiment. The results indicated that the changes in glass deflection increase with temperature increase. Glass stretching is more pronounced with heating cycle time. The rate of combustion of glass curvature would be affected at a higher room temperature, and the rate of heat absorption temperature on float glass combustion is higher.
\end{abstract}

Keywords: Windshield, forming process, deflection, float glass, furnace

\section{INTRODUCTION}

Sometimes, the forming process of the front windshield needs to be traditionally made on cars for broken glass accidents. In addition to avoiding high costs, it is not directly easy to have an original part for replacing it. It takes a longer time to have an original windshield. The forming process of float glass to be front windshield is an easy way to modify in replacing it. It is also inexpensive to realise it.

In general, glass is a fragile material and not elastic. Glass has a higher compression strength than its tensile strength. Fragility and strength of the glass affect its application in the field, where the potential for fractures can occur due to static and dynamic load effects. The glass industry consumed substantial energy in high temperature of melting processes up to $1600^{\circ} \mathrm{C}$ [1][2]. Glass material contained one type of functional crystalline phase and glass residue [3]. The properties of glass were largely influenced by the uniqueness of silica $\left(\mathrm{SiO}_{2}\right)$ and its formation process.

Numerous studies of characteristic of a float glass have been investigated experimentally [4][5] and numerically [6][7].A laminated float glass was commonly used for car front windshield. Some researchers have addressed the problem in laminated float glass such as level dependency for monolithic and laminated glass in a predictive strength model[8]. A study with static modelling shown that float glass increased variability between 1.29-1.58 and hard floating glass decreased variability between 0.63-0.76 [9]. An increase in thickness between layers from 0.38 to 0.76 $\mathrm{mm}$ increased delamination, whereas a further increase in thickness between layers at higher values had a lower effect [10].

The heat treatment of burning glass had a dominant problem in terms of the aspect of high time consumption, but low energy consumption and production costs, thus requiring an alternative process in its development [11]. With temperature control techniques in active thermal systems that were able to adapt to changing environmental conditions, Baumgartner et al.[12]found a type of fluid glass that considered four functions or used in one element. A study using a combination of metal and ceramic noted that thermal and thermomechanical loadings were key important factors to address the functionally graded material in high temperature environment[13].

A study stated that glass damage was generally caused by increased glass tension due to rising temperatures in glass combustion [14][15]. The thermodynamic properties of glass that were unstable cause the glass to continuously absorb heat, so it needed to be neutralized back to its original state. Measurement of natural frequency to assess the mechanical response of the glass panel was to be important to evaluate the non-linear characteristics of the glass and the nature of the material in the analysis of the bending point of the glass [16][17].

Heat treatment on glass was developed to improve the quality of glass. Heat treatment was a common practice for improving glass quality. In the process, the glass plate was heated with forced convection thermal flow up to about $640 \mathrm{C}$ and then the cooling rate was carried out depending on the thickness of the glass, the coordinates of the flow and the cooling time[18][19].

This paper discusses the characteristics of float glass in the heat treatment process at a thickness of $5 \mathrm{~mm}$ in a heating furnace. Heat treatment was performed by the method of combustion in a heating furnace up to 30-60 minutes, where the glass was heated by combustion between 400$600 \square$ C. Therefore, the surface of the whole glass undergoes changes in deflection.

\section{MATERIAL AND METHOD}

This study was performed at laboratory of Manufacturing Process Universitas Muhammadiyah Pontianak Indonesia. The characteristics investigation of float glass was carried out in two stages, namely glass bending and testing for 
glass bending. Temperature variation testing was performed in the glass bending process in order to determine the maximum temperature of the curvature and glass arches. As a reference in making test specimen, Figure 1 is part of the dimensions of the glass with a thickness of $5 \mathrm{~mm}$.

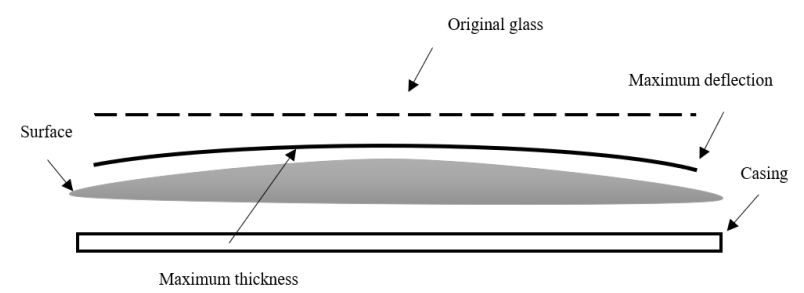

Figure 1: Sketch of specimen and components.

The raw material in the study was float glass in the form of sheet shapes of 2,000 $\mathrm{mm} \times 2,000 \mathrm{~mm} \times 5 \mathrm{~mm}$. Additional materials in the manufacture of float glass included zip sand, silica sand, river sand, used oil and diesel fuel.

High furnace temperatures, glass and fuel after initial use to the end shown in table 1 thatrepresents the operating temperature at a fluid and a solid material.

Table 1: Glass Bending Process

\begin{tabular}{lcc}
\hline \multirow{2}{*}{ Materials } & \multicolumn{2}{c}{ Temperature $\left({ }^{\circ} \mathrm{C}\right)$} \\
\cline { 2 - 3 } & Initial & Final \\
\hline Combustion process & 34.9 & 127.5 \\
Glass & 30.6 & 42.5 \\
Fuel & 30.5 & 36.2 \\
\hline
\end{tabular}

Figure 2 illustrates the mould preparation for the windshield forming process. Skill and precision mouldwere needed to reach accurate results. The printing of the windshield begun with cutting the glass according to the size and shape that has been measured on the front side of the minibus car at a glass radius of about $10-15^{\circ}$, as shown in Figure 3. The process of burning and bending the glass was carried out in a high temperature heating furnace.

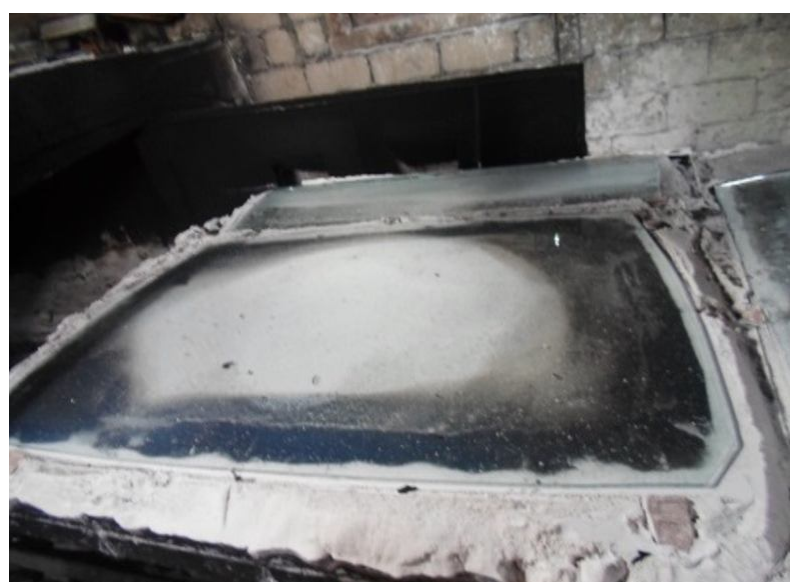

Figure 2: Specimen of windshield

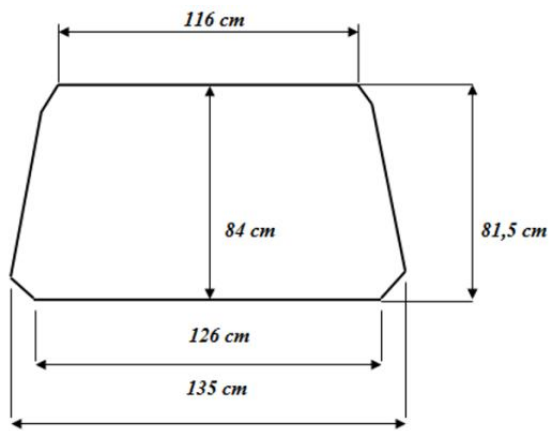

Figure 3: Dimension of windshield specimen

Figure 4 shows the combustion and glass bending process carried out in a high temperature heating furnace. After the temperature of the glass reaches a temperature of $400^{\circ} \mathrm{C}$, the glass undergoes a curving process following the print pattern in the furnace. Figure 5 demonstrates a measurement of temperature using thermocouple through the fire control hole in a traditional furnace.

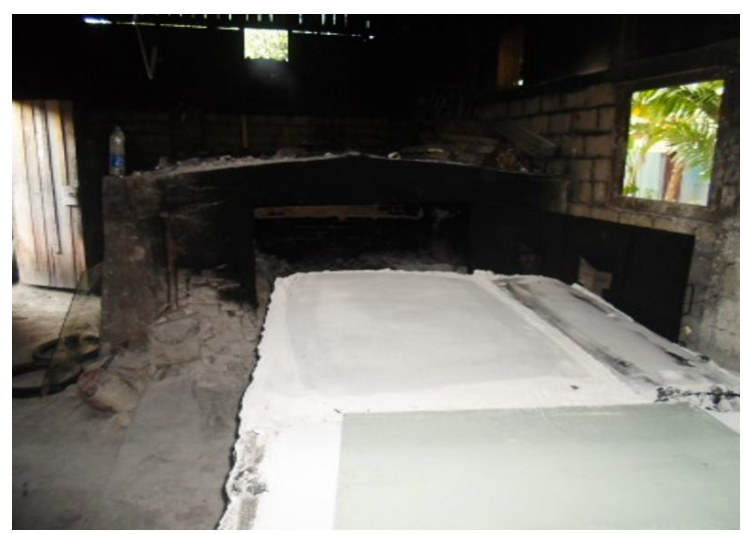

Figure 4: Traditional Furnace

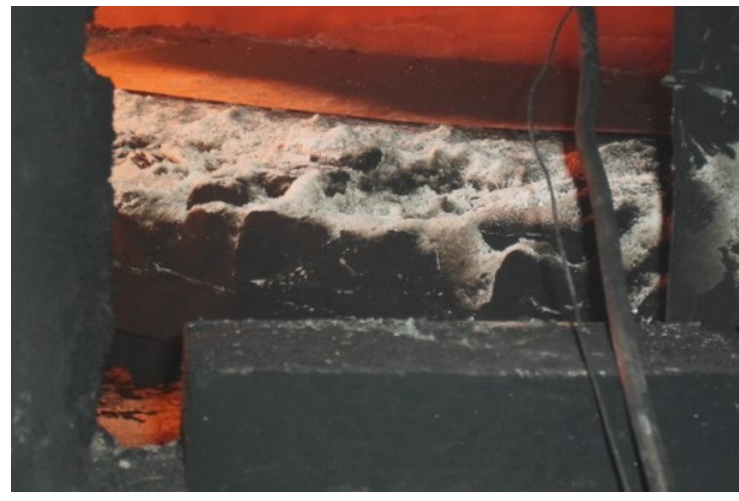

Figure 5: Fire control

\section{RESULTS AND DISCUSION}

The changes of float type flat glass due to heat around the glass surfacehas been investigated in a traditional furnace. Some parameters such as glass deflection and dimension have been carefully assessed. The results and discussion are as follow: 
Eko Julianto et al., International Journal of Emerging Trends in Engineering Research, 8(5), May 2020, 2173 - 2176

\subsection{Deflection of float glass}

The deflection measurement data of windshield specimen refers to definition of deflection as given in Figure 1. Based on experiment, Figure 6 shows the changes in deflection $(\Delta \mathrm{L})$ of float glass specimen after heating process in the furnace. The changes in float glass deflection increase with increasing the temperature. This is more apparent at increasingly high temperatures. It is reasonable due to the thicker material is more difficult to have deflection.

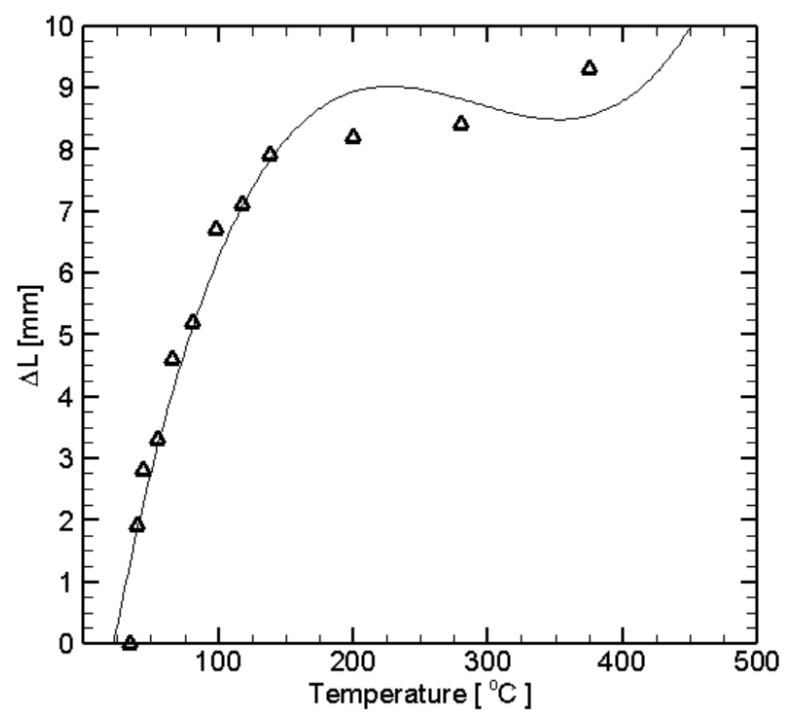

Figure 6: Deflection of float glass

\subsection{Dimension of float glass}

Based on the initial dimension of windshield specimen in Figure 3, the change in dimension was observed during the heating process. Strain gauges were used to measure the glass stretching. Figure 7 displays the changes in dimension of windshield specimen along the heating process in the furnace. The stretching of the glass is more pronounced with time of the heating process. During 60 minutes, the expansion of windshield dimension is increased by about 1.96 per cent.

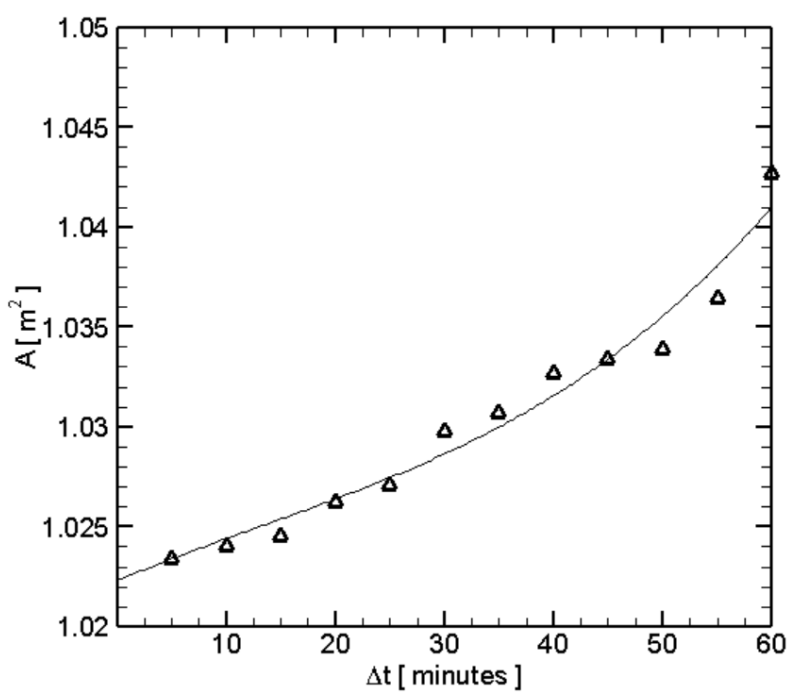

Figure 7: Dimension of float glass

\subsection{Profile of float glass}

Figure 8 illustrates the step-by-step changes in the dimensions of glass specimen during changes in glass deflection from $1.9^{\circ}$ to $11.2^{\circ}$.
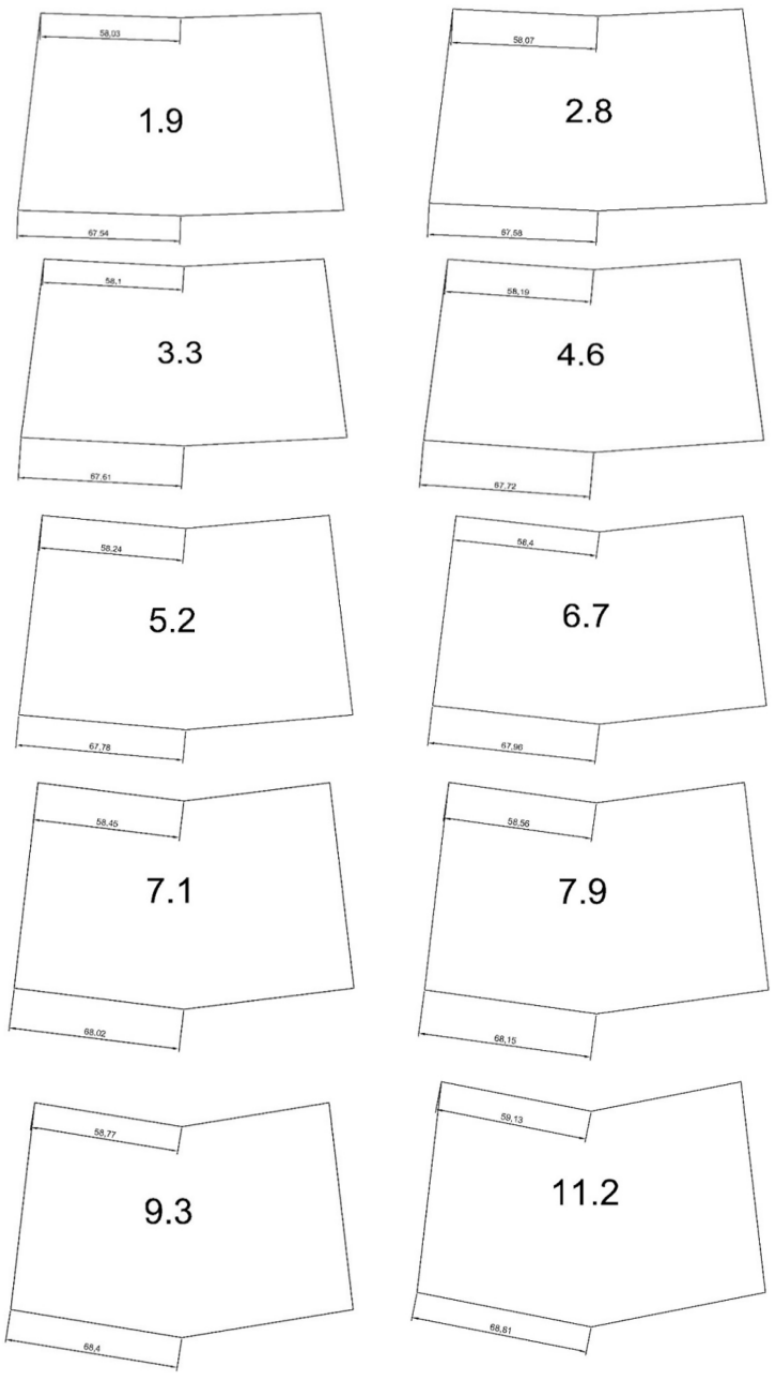

Figure 8: Profile of float glass

The measurement of deformation and deflection is shown in table 2 .

Table 2: Glass Bending Process

\begin{tabular}{|c|c|c|c|c|c|c|c|}
\hline \multirow[b]{2}{*}{ Time } & \multicolumn{3}{|c|}{ Temperature $\left({ }^{\circ} \mathrm{C}\right)$} & \multirow[b]{2}{*}{$(\Delta \mathbf{L})$} & \multirow[b]{2}{*}{$\begin{array}{c}\mathbf{A} \\
\left(\mathrm{m}^{2}\right)\end{array}$} & \multirow[b]{2}{*}{$\begin{array}{l}\Delta \mathbf{T} \\
(\mathbf{K})\end{array}$} & \multirow[b]{2}{*}{ (minutes) } \\
\hline & $\begin{array}{c}\text { Glass } \\
\text { In }\end{array}$ & $\begin{array}{c}\text { In } \\
\text { Furnace }\end{array}$ & $\begin{array}{c}\text { Glass } \\
\text { Out }\end{array}$ & & & & \\
\hline 14.05 & 32.3 & 34.9 & & 0 & 1.0228 & 0 & 0 \\
\hline 14.10 & & 39.3 & & 1.9 & 1.0234 & 278.4 & 5 \\
\hline 14.15 & & 44.0 & & 2.8 & 1.024 & 278.7 & 10 \\
\hline 14.20 & & 55.0 & & 3.3 & 1.0245 & 285 & 15 \\
\hline 14.25 & & 66.3 & & 4.6 & 1.0262 & 285.3 & 20 \\
\hline 14.30 & & 80.7 & & 5.2 & 1.0271 & 288.4 & 25 \\
\hline 14.35 & & 98.2 & & 6.7 & 1.0298 & 291.5 & 30 \\
\hline 14.40 & & 117.8 & & 7.1 & 1.0307 & 293.6 & 35 \\
\hline 14.45 & & 138.5 & & 7.9 & 1.0327 & 294.7 & 40 \\
\hline 14.50 & & 200.3 & & 8.2 & 1.0334 & 335.8 & 45 \\
\hline 14.55 & & 280.2 & & 8.4 & 1.0339 & 353.9 & 50 \\
\hline 15.00 & & 375.8 & & 9.3 & 1.0364 & 369.6 & 55 \\
\hline
\end{tabular}




\section{CONCLUSION}

Thecharacteristics of float type flat glass widely used in car front windshield forming process were investigated experimentally. It can be summarised that the glass deflection changes increase with increasing temperature. With heating cycle time, stretching of the glass is more pronounced. At higher room temperature, the rate of combustion of glass curvature will be affected, and the rate of heat absorption temperature on the combustion of float glass is greater.

\section{ACKNOWELDGEMENT}

The authors would like to acknowledge the facilities from Universitas Muhammadiyah Surakarta and Universitas Muhammadiyah Pontianak, Indonesia in supporting this collaborative research.

\section{REFERENCES}

[1] K. Tapasa and T. Jitwatcharakomol, "Thermodynamic calculation of exploited heat used in glass melting furnace," Procedia Eng., vol. 32, pp. 969-975, 2012, doi: 10.1016/j.proeng.2012.02.040.

[2] A. Nyounguè, S. Bouzid, E. Dossou, and Z. Azari, "Fracture characterisation of float glass under static and dynamic loading," J. Asian Ceram. Soc., vol. 4, no. 4, pp. 371-380, 2016, doi: 10.1016/j.jascer.2016.07.004.

[3] J. Deubener et al., "Updated definition of glassceramics," J. Non. Cryst. Solids, vol. 501, pp. 310, 2018, doi: 10.1016/j.jnoncrysol.2018.01.033.

[4] Y. Zhang, Q. S. Wang, X. Bin Zhu, X. J. Huang, and J. H. Sun, "Experimental study on crack of float glass with different thicknesses exposed to radiant heating," Procedia Eng., vol. 11, pp. 710718, 2011, doi: 10.1016/j.proeng.2011.04.717.

[5] S. Park, A. Carriquiry, L. K. Horkley, and D. W. Peate, "A database of elemental compositions of architectural float glass samples measured by LAICP-MS," Data Br., vol. 30, 2020, doi: 10.1016/j.dib.2020.105449.

[6] K. Osnes, J. K. Holmen, O. S. Hopperstad, and T. Børvik, "Fracture and fragmentation of blastloaded laminated glass: An experimental and numerical study," Int. J. Impact Eng., vol. 132, no. 7491, p. 103334, 2019, doi: 10.1016/j.ijimpeng.2019.103334.

[7] E. Julianto, W. A. Siswanto, and M. Effendy, "Characteristics of temperature changes and stress of float glass," Int. J. Emerg. Trends Eng. Res., vol. 7, no. 9, pp. 228-233, 2019.

[8] K. Osnes, O. S. Hopperstad, and T. Børvik, "Rate dependent fracture of monolithic and laminated glass: Experiments and simulations," Eng. Struct., vol. 212, no. February, p. 110516, 2020, doi: 10.1016/j.engstruct.2020.110516.

[9] K. P. Rushton, S. A. Coulson, A. W. N. Newton, and J. M. Curran, "The effect of annealing on the variation of glass refractive index," Forensic Sci. Int., vol. 209, no. 1-3, pp. 102-107, 2011, doi: 10.1016/j.forsciint.2011.01.006.

[10] A. Vedrtnam, "Experimental and simulation studies on delamination strength of laminated glass composites having polyvinyl butyral and ethyl vinyl acetate inter-layers of different critical thicknesses," Def. Technol., vol. 14, no. 4, pp. 313-317, 2018, doi: 10.1016/j.dt.2018.02.002.

[11] L. Altan and G. Waibel, "New process of tempering color printed glass by using laser irradiation," Procedia CIRP, vol. 74, pp. 390-393, 2018, doi: 10.1016/j.procir.2018.08.154.

[12] L. Baumgärtner, R. A. Krasovsky, J. Stopper, and J. von Grabe, "Evaluation of a solar thermal glass façade with adjustable transparency in cold and hot climates," Energy Procedia, vol. 122, pp. 211216, 2017, doi: 10.1016/j.egypro.2017.07.347.

[13] M. Bhandari, "Impact of variable thermal and hhermomechanical environment on graded FGM square plate," Int. J. Emerg. Trends Eng. Res., vol. 8, no. 4, pp. 1005-1010, 2020.

[14] Q. S. Wang, Y. Zhang, J. H. Sun, J. Wen, and S. Dembele, "Temperature and thermal stress simulation of window glass exposed to fire," Procedia Eng., vol. 11, pp. 452-460, 2011, doi: 10.1016/j.proeng.2011.04.682.

[15] Q. Wang, H. Chen, Y. Wang, and J. Sun, “Thermal shock effect on the glass thermal stress response and crack propagation," Procedia Eng., vol. 62, pp. 717-724, 2013, doi: 10.1016/j.proeng.2013.08.118.

[16] L. Sable, E. Skukis, G. Japins, and K. Kalnins, "Correlation between numerical and experimental tests of laminated glass panels with visco-elastic interlayer," Procedia Eng., vol. 172, pp. 945-952, 2017, doi: 10.1016/j.proeng.2017.02.107.

[17] J. C. Mauro and M. M. Smedskjaer, "Statistical mechanics of glass," J. Non. Cryst. Solids, vol. 396-397, pp. 41-53, 2014, doi: 10.1016/j.jnoncrysol.2014.04.009.

[18] B. W. Stuart, M. Gimeno-fabra, J. Segal, I. Ahmed, and D. M. Grant, "Mechanical, structural and dissolution properties of heat treated thin-film phosphate based glasses," Appl. Surf. Sci., vol. 416, pp. 605-617, 2017, doi: 10.1016/j.apsusc.2017.04.110.

[19] G. Tunjai, A. Chotipong, and C. Sutthirat, "The leachate of lead from the crucibles undergone ruby heat treatment with lead glass additive," $A P C B E E$ procedia, vol. 10, pp. 91-95, 2014, doi: 10.1016/j.apcbee.2014.10.023. 